\section{Response to: 'Criteria for CAPS, is it all in the name?' by Touitou and Sarrabay}

We thank the authors of the eletter 'Criteria for CAPS, is it all in the name?' 1 for her very thoughtful comments on how to best define and name the autoinflammatory diseases we currently call cryopyrin-associated periodic syndromes-CAPS. The author very eloquently elaborate on some of the challenges we face when caring for children and adults with autoinflammatory diseases. Traditionally, disease names have highlighted the specific clinical phenotype-familiar cold-induced urticaria-or marked the name of the physicians, who first recognised a distinct disease entity-Muckle-Wells syndrome, Kawasaki disease. The discovery of a common genetic cause for the spectrum of illnesses we now label CAPS has changed this approach assuming a solid genotype-phenotype correlation. Subsequent disease names have followed this path-STING-associated vasculopathy with onset in infancy, haploinsufficiency of A20 and others. We may have hopefully assumed that patients with the clinical diagnosis of CAPS always have a disease-causing genetic variant in the NLRP3 gene and vice versa. The author summarises carefully the diversity of genes associated with the diversity of clinical phenotypes in CAPS.

Our team chose a clinical approach. All team members care for children and adults with autoinflammatory diseases in different parts of the world and conduct research to improve the disease outcomes. The desire of the team was to enable a rapid diagnosis of the diseases in the clinical spectrum of CAPS to initiate treatment and prevent irreversible organ diseases. When conducting this rigorous exercise, we rejected the idea of classification criteria for research studies and the consideration of a mandatory genetic confirmation. For validation we did not choose genetically defined cohorts; the focus was the clinical phenotype and the true differential diagnosis in clinical practice. $^{2}$

There are limitations to any approach we choose to take. For our team, children and adults suffering from the clinical phenotype of CAPS were the priority. We are all aware that confirming a diagnosis and giving a name is often the key for access to life and organ saving, expensive medications. The discussion around the best name for autoinflammatory diseases-capturing clinical entities versus genetic entities-is important. We thank the author again for her very thoughtful letter.

\section{Jasmin B Kuemmerle-Deschner, ${ }^{1}$ Susanne M Benseler ${ }^{2}$}

${ }^{1}$ Division of Pediatric Rheumatology, Department of Pediatrics, University Hospital Tübingen, Tübingen, Germany

2Division of Rheumatology, Department of Pediatrics, Alberta Children's Hospital/ University of Calgary, Calgary, Alberta, Canada

Correspondence to Dr Jasmin B Kuemmerle-Deschner, Division of Pediatric Rheumatology, Department of Pediatrics, University Hospital Tübingen, HoppeSeyler-Str. 3, Tübingen 72076, Germany; kuemmerle.deschner@uni-tuebingen.de

Competing interests None.

Provenance and peer review Not commissioned; externally peer reviewed.

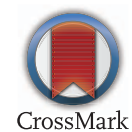

To cite Kuemmerle-Deschner JB, Benseler SM. Ann Rheum Dis 2017;76:e10.

Received 7 November 2016

Revised 8 November 2016

Accepted 9 November 2016

Published Online First 29 November 2016

\section{Linked}

http://dx.doi.org/10.1136/annrheumdis-2016-210681

Ann Rheum Dis 2017;76:e10. doi:10.1136/annrheumdis-2016-210726

\section{REFERENCES}

1 Touitou I, Sarrabay G. Criteria for CAPS, is it all in the name? Ann Rheum Dis 2017;76:e9.

2 Kuemmerle-Deschner JB, Ozen S, Tyrrell PN, et al. Diagnostic criteria for cryopyrin-associated periodic syndrome (CAPS). Ann Rheum Dis 2016; Published Online First 4 October 2016. 